IZA DP No. 8970

Impact of Hospital Delivery on Child Mortality: An Analysis of Adolescent Mothers in Bangladesh

Sarmistha Pal

April 2015 


\title{
Impact of Hospital Delivery on Child Mortality: An Analysis of Adolescent Mothers in Bangladesh
}

\author{
Sarmistha Pal \\ University of Surrey \\ and IZA \\ Discussion Paper No. 8970 \\ April 2015 \\ IZA \\ P.O. Box 7240 \\ 53072 Bonn \\ Germany \\ Phone: +49-228-3894-0 \\ Fax: +49-228-3894-180 \\ E-mail: iza@iza.org
}

\begin{abstract}
Any opinions expressed here are those of the author(s) and not those of IZA. Research published in this series may include views on policy, but the institute itself takes no institutional policy positions. The IZA research network is committed to the IZA Guiding Principles of Research Integrity.

The Institute for the Study of Labor (IZA) in Bonn is a local and virtual international research center and a place of communication between science, politics and business. IZA is an independent nonprofit organization supported by Deutsche Post Foundation. The center is associated with the University of Bonn and offers a stimulating research environment through its international network, workshops and conferences, data service, project support, research visits and doctoral program. IZA engages in (i) original and internationally competitive research in all fields of labor economics, (ii) development of policy concepts, and (iii) dissemination of research results and concepts to the interested public.
\end{abstract}

IZA Discussion Papers often represent preliminary work and are circulated to encourage discussion. Citation of such a paper should account for its provisional character. A revised version may be available directly from the author. 


\section{ABSTRACT \\ Impact of Hospital Delivery on Child Mortality: An Analysis of Adolescent Mothers in Bangladesh*}

The present paper provides new evidence that hospital delivery can significantly lower child mortality risks, especially among vulnerable young adolescent mothers in Bangladesh. We exploit the exogenous variation in community's access to local health facilities (both traditional and modern) before and after the completion of the 'Women's Health Project' in 2005 (that enhanced emergency obstetric care in women friendly environment) to identify the causal effect of hospital delivery on various mortality rates among children born during 20022007. Our best estimates come from the parents fixed effects models that help limiting any parents-level omitted variable estimation bias. Ceteris paribus, access to family welfare clinic boosts hospital delivery likelihood, which in turn tends to lower neo-natal, early and infant mortality rates, especially among adolescent mothers after the completion of Women's Health Project.

JEL Classification: D13, I12, O15

Keywords: Women's Health Project, emergency and obstetric care, adolescent mothers, household fixed effects models, endogeneity and identification, access to health facilities, infant and child mortality indices

Corresponding author:

Sarmistha Pal

Surrey Business School

University of Surrey

Guildford GU2 7XH

United Kingdom

E-mail: s.pal@surrey.ac.uk

\footnotetext{
* This research has been conducted at the University of Surrey and I would like to thank the University for the research facilities over this time. I would like to thank Demographic Health Survey Organisation for help with the access to the data and also help with various data queries. I have benefitted from discussions with Gerald Makepeace, Pushkar Maitra, Stan Panis, and Zaki Wahhaj at various stages of the paper while I am solely responsible for any remaining errors.
} 


\section{Impact of Hospital Delivery on Child Mortality:}

\section{An Analysis of Adolescent Mothers in Bangladesh}

\section{Introduction}

With scientific and technological advancements such as vaccines and diagnostic methods, the potential to save children's lives continues to expand. Emergence of effective interventions is, however, not enough by itself unless they reach the children and mothers who need them most (Bryce et al. 2003). In this paper we assess the causal impact of a direct public health intervention, namely, institutional/hospital (as opposed to home) delivery on mortality risks among children aged five or below. Mortality risks are concentrated around the time of birth: a quarter of all neonatal birth takes place within first twenty four hours of birth and three quarter within the first week (WHO 2006). The underlying rationale for encouraging births in health facilities as opposed to home delivery is that it gives mothers access to trained health professionals, who are better able to recognize and manage delivery complications and perform essential and timely interventions using modern diagnostic tests, medicines as well as new born resuscitation (Filippi et al., 2006). We are particularly interested to assess the effect on adolescent mothers, who bear additional risks: using demographic health survey data from fifteen developing countries Reynolds et al. (2006) found that compared to babies born to women aged 20-29 years, babies born to women younger than 20 have a 34 percent higher risk of death in the neonatal period, largely because of their increased risk of being low-birth-weight, and a 26 percent higher risk of death by age five.

Bangladesh is an important case in point. Despite its success in meeting the Millennium Development Goal (MDG) (48 per 1,000 live births in 2015) of reducing child mortality by $2015^{1}$, and also some success of reducing the infant mortality rate, there remain important inequalities: its 120,000 annual newborn deaths account for more than half (55 percent) of Bangladesh's under- 5 child deaths in

\footnotetext{
${ }^{1}$ The successful programs for immunization, control of diarrhoeal diseases and Vitamin A supplementation are considered to be the most significant contributors to the decline in child and infant deaths along with potential effect of overall economic and social development.
} 
2007 and impede the country's progress towards the MDG of reducing the infant mortality rate by 2015 (Planning Commission 2013). ${ }^{2}$ Increasing child survival rates, especially in the neonatal period, is therefore an issue of significant concern. To a large extent, this high incidence of infant mortality in the country is related to early marriage and early childbirth (Akter et al., 2007). In particular, our analysis considers the impact of hospital delivery before and after the completion of Women's health project in 2005 that strengthened the emergency obstetric care (EmOC) in a woman's friendly environment (see further details in section 2). ${ }^{3}$

A variety of policies have been adopted to protect the interests of young yet high risk mothers including girls' scholarship to ensure girls' school completion (which may in turn delay child birth), introduction of laws relating to the minimum age at marriage, incentives to increase contraceptive use (see Schuler et al. 2005) in Bangladesh. Indirect policies of this nature have had limited success for a number of reasons: (i) there are issues of sustaining the short run gains. (ii) There are social costs associated with some of these policies, which are not fully taken into account. ${ }^{4}$ The present paper thus advocates for a more direct public health policy intervention, namely hospital/institutional (as opposed to home) delivery, which may yield immediate effect. The fact that most mothers (an overwhelming 85\% in the 2007 demographic health survey; our calculation) deliver at home without a skilled attendant means that few resources are available for neonatal care in cases of complications. Often home deliveries take place in the presence of female family members (sometimes in the presence of traditional birth attendants (dais)), in unhygienic conditions, thus increasing the chance of infection in both the mother and the child. The situation is worse among young adolescent mothers: it is well documented (e.g., see Senderowitz and Paxman, 1985) that there are adverse physical/health consequence of early

\footnotetext{
2 The situation is particularly worse in Bangladesh as compared to her South Asian neighbours. For example, as of 2006, the infant mortality rate in Bangladesh was 52.5 per thousand live births, compared to 30.15 per thousand live births in India and 18.57 per thousand live births in Sri Lanka around the same time. http://en.wikipedia.org/wiki/List_of_countries_by_infant_mortality_rate

${ }^{3}$ http://www.unicef.org/bangladesh/health_nutrition_407.htm.

${ }^{4}$ For example, while it is true that each additional year of delayed marriage in Bangladesh is associated with 0.30 additional years of schooling and 6.5\% increase in the probability of being literate, it also comes at the cost of substantial increase in dowry (see for example Field and Ambrus, 2008). Similarly, introduction of family planning is found to be associated with 80\% rise in dowry in Bangladesh (Arunachalam and Naidu, 2008). 
child bearing for both the mother (for example anaemia, haemorrhage, sepsis, preeclampsia, obstructed labour) and the baby (e.g., low birth-weight, malnutrition, early death). Young mothers are also less likely to be knowledgeable enough to adequately care for her child.

Arguably, institutional delivery may help averting premature death of young children. There are however two important considerations here: (i) Supply: the market for health care in Bangladesh is characterised by coexistence of modern (provided in hospital and other health facilities, public or private) and traditional (faith-based or herbal based) health care (Haque et al. 2014). The likelihood of hospital delivery then depends not only on access to various modern health care facilities in the locality, but also access to traditional health care facilities which offers an additional health care choice to households. (ii) Demand: Choice of a specific type of health care not only depends on its access, but also on the demand forces, ${ }^{5}$ which depend on the underlying costs and household budget constraints. Although 'free', use of public health facilities may entail costs on various accounts: there are high outof pocket expenses for modern health inputs (e.g., see Costello and Nahar, 1998) available in public health facilities (especially high and rising prices of modern medicine), poor access to quality public care (Chaudhary and Hammer, 2004), absence of women friendly environment in public facilities even when it is accessible. In contrast, traditional health care, e.g., faith based Unani facilities, is likely to be cheaper in terms of prices paid; it may also be more appealing to households with traditional religious values, e.g., people with Islamic faith. In reality, we observe the realized health care choice (as reflected in hospital or home delivery) of children as well as child health among other consumption goods, determined by both supply and demand considerations described above (see further discussion in section 3). This structure helps explaining a coexistence of traditional and modern health care facilities in a country like Bangladesh.

Our final aim is to assess the impact of hospital delivery on child health measured by various mortality risks. Identification of the effect of hospital or more generally institutional delivery on child mortality is thus likely to be econometrically challenging because of the inherent simultaneity: just as

\footnotetext{
${ }^{5}$ In theory, household optimal health care choice is determined by maximizing utility derived from the choice of consumption and health goods, subject to the budget constraints, within a Beckerian framework.
} 
choice of institutional/home delivery affects child mortality, likelihood of child mortality may also influence choice of institutional delivery. Many existing studies thus suffer from the underlying estimation bias while assessing the impact of institutional delivery (or related proxies) on health outcomes and find both positive and negative effects of choice of health inputs (see discussion below). We adopt a novel approach here and exploit the exogenous variation in access to local health facilities, both traditional and modern, to instrument hospital delivery. Our analysis is based on the 2007 Bangladesh Demographic Health Survey (BDHS), which was the first round that provided information on access to different types of health modern (including hospitals, maternal and child welfare centres (mcwc), thana health centre (thc) and family welfare centre (fwc)) and traditional (unani and/or ayurvedic) facilities. Since a woman's choice of institutional delivery is unlikely to be random in the determination of child mortality, we first determine hospital delivery in terms of exogenous variation in the access to these traditional and modern health facilities at the local level (defined by the primary sampling unit), which is beyond the control of the individual households and use the predicted value of the variable as a valid instrument to determine the causal effect of institutional delivery on early, neonatal, infant and child mortality indices among children born during 2002-07, paying specific attention to those born to young adolescent mothers. We also compare the effect of hospital delivery on child mortality before (2002-05) and after (2006-07) the completion of the Women's Health Project in 2005 (see further details in sections 2-4).

Our analysis contributes to a limited but growing literature on the use of health inputs on child health outcomes in developing countries. The literature is somewhat diverse in the choice of specific health inputs (pre-natal medical care, hospital delivery or presence of skilled birth attendant) as well as index of child health outcome (mortality risks, birth weight etc.). Panis and Lillard (1994) and Maitra (2004) both identified that prenatal medical care and institutional delivery have strong beneficial effects on child survival in Malaysia and India respectively, while using a meta-analysis Dharamstadt et al. (2011) find a negative effect of skilled birth attendant on child health outcome. None of these studies however redress the estimation bias arising from endogeneity of health input chosen by households. More recently, Randive et al. (2014) find that although inequality in access to institutional delivery care 
persists in India, its extent has reduced since the introduction of Janani Swastha Yojana (JSY) in 2005 that promotes institutional delivery by offering a financial incentive of Rs. 500/- available uniformly throughout the country to poor pregnant women holding below poverty line (BPL) status. Mazumdar et al. (2011) exploit spatial and temporal variation in introduction of the Janani Suraksha Yojana program in India at the district level and find no effect of the program on either neonatal mortality (defined as deaths within 28 days), or early neonatal mortality (defined as deaths within the first 24 hours), despite a statistically significant increase in the rate of institutional deliveries.

Our best estimates come from the household fixed effects estimates that limits the potential estimation bias arising from household-level omitted factors. Among various health facilities, access to local family welfare clinic significantly enhances the likelihood of institutional delivery, ${ }^{6}$ while age at birth increases with factors that boosts mother's bargaining power, e.g., mother's membership of various micro-finance/self-help groups, husband's age and also if she is the wife of the head of the household. Ceteris paribus, institutional delivery is associated with significantly lower incidence of early, neonatal and infant mortality rates, especially after the completion of the WHP. We argue that the particularly beneficial role of family welfare centres (relative to other possible health facilities) in this respect is likely to be related to their greater accessibility (see Appendix table 1) and women's friendly nature that offers more privacy (Cockcroft et al. 1999). Second, we show that institutional delivery is particularly beneficial for saving lives of newborn children (within the first year) born to adolescent mothers, as this ensures adequate and timely (relative to home delivery) medical attention. ${ }^{7}$ Finally, compared to children born during 2002-05, those born during 2006-07, after the completion of the Women's Health Project that strengthened Emergency Obstetric Care and offered more

\footnotetext{
${ }^{6}$ Access to other health facilities however does not seem to matter as they are much less accessible to most households (see further discussion in section 4).

${ }^{7}$ Given the potential endogeneity of mother's age at birth, we use indices of women's bargaining power (e.g., membership of micro-finance or self-help groups, being the wife of the head of the household and also husband's age) and also her awareness of health issues (measured by her listening to tv/radio daily) to determine age at birth, another endogenous variable.
} 
women-friendly environment in the public health facilities, are less likely to die even if they are born to adolescent mothers, but only if these mothers choose to deliver in a health facility.

While Chaudhary and Hammer (2004) highlight the problems of unfilled positions, absenteeism especially among doctors (the problem is relatively less among nurses, paramedics and other lower ranking health professionals) in Bangladesh (also see Banerjee and Duflo, 2006 for the general problem absenteeism in developing countries), our results highlight the potential efficacy of institutional delivery as a direct public health intervention (relative to other medium and long-term interventions) that saves lives of newborn children, ${ }^{8}$ especially among adolescent mothers in Bangladesh.. This can be possible in a number of ways: (a) many of these public services may not be running in full capacity, but it still may be able to provide some services, especially in the mornings when doctors are more likely to be present. (b) Women's Health Project particularly emphasized the training of local medical officers as well as other health professionals including skilled birth attendants to provide the essential medical support at birth, thus reducing the reliance on absentee doctors (WHO 2007). (c) Further, one cannot rule out the possibility that the absent public doctors/nurses may in fact be providing services in the private sector in the locality (Chaudhury and Hammer, 2004). This is an encouraging development though there is still work to be done to make these health facilities fully functional as well as provide help easing the out of pocket expenses of institutional delivery, especially for the poor.

\section{Background, Data and Descriptive Statistics}

\subsection{Background}

Since 1975, the government of Bangladesh has put consolidated efforts to develop its integrated health and family planning programme. The country is divided into six administrative divisions, 64 districts (Zilas), and 507 sub-districts (Thanas or Upazilas). About $80 \%$ of the country's population

\footnotetext{
${ }^{8}$ In particular, we show that institutional delivery can help averting about $26 \%$ child deaths among adolescent mothers within the first month of child birth (see further discussion in section 4).
} 
lives in rural areas and are served by a combination of health facilities including district hospitals, maternal and child welfare centre (union, district and sub-district level), sub-district level health centres (thc) and also the union family welfare centres (fwc) as summarised in Appendix Table A1.

These health facilities are served by different types of health professionals with varying levels of training including doctors (medical school graduates), nurses (with 4 year training), medical Officers - paramedics (minimum 3 years training), Family Welfare Visitors (FWVs) and Senior FWVs (minimum 18 month training), pharmacists and lab technicians. In some areas where government facilities are not functioning, services are provided by NGOs operating one or more static clinics. The government and NGOs also run satellite clinics that are regularly organized by field workers in communities to increase accessibility to health services. There is also a growing presence of private health care services which includes private-for-profit clinics (mainly operative in urban areas) and also private pharmacies; however, its high out of pocket expenditure (and also unpredictable quality of care) means the poor have limited access to these private facilities (Begum et al., 2000).

Table 1 summarises the overall reproductive and child health statistics in Bangladesh around 2007; among other things, the table highlights that as high as $90 \%$ of child birth took place in home and in 77\% case there was a traditional (and not modern medically trained) birth attendant. Overall child mortality risks vary between 4-7\% though the corresponding risks are much higher among the first born children in our sample.

In an attempt to achieve the health related MDGs, Ministry of Health and Family Welfare Bangladesh launched the Women's Health Project in association with the United Nations International Children's Emergency Fund (UNICEF) in the new Millennium, aiming to be completed by 2005. The aim of the project was to ensure women's right to survival with respect, dignity and self-esteem. It had three sub-projects: strengthening Emergency Obstetric Care, Women-Friendly Hospital Initiative (WFHI) and Social Mobilisation and Communication with a view to attain the following objectives by 2005: (i) increase antenatal care coverage to 60 per cent and postnatal care coverage to 30 per cent; (ii) increase emergency obstetric care (EmOC) to 40 per cent; (iii) increase proportion of deliveries assisted 
by skilled personnel to 25 per cent; (iv) Establish comprehensive EmOC at all district hospitals and at 30 per cent of sub-district hospitals; (v) improve social behaviour of health service staff in their interactions with women and thus make hospitals women friendly. This initiative has developed an environment, which enables women to receive treatment in privacy and with dignity and respect.

An integral part of the project has been to provide twenty four hour comprehensive EmOC services. Life saving services (signal functions) for direct obstetric complications include: administration of parenteral 1) antibiotics, 2) oxytocics and 3) anticonvulsants; 4) manual removal of placenta; 5) removal of retained products; 6) assisted vaginal delivery; 7) cesarean section (CS); and 8) blood transfusion. A Basic EmOC facility is one that provides signal functions $1-6$ while a Comprehensive EmOC (CEmOC) facility is one that provides all 8 signal functions. If accessible, these services can save lives of both the mother and the child.

The empirical analysis in the present paper is based on the 2007 round Bangladesh Demographic and Health Survey (BDHS) which allows us to observe children born in the last five years 2002-07 of the survey. Accordingly, we consider the effect of the completion of the Women's Health Project by comparing child health outcomes before (2002-2005) and after (2006-07) 2005. A simple analysis of the data highlights the effectiveness of the programme in that hospital delivery rate increased from about $13.6 \%$ during $2002-05$ to $20.5 \%$ after the completion of the WHP (the difference is statistically significant with a p-value $=0.000$ ). The government was totally committed and had ensured synchronization of the various inputs required for establishing functioning centres. This is corroborated by UNICEF Bangladesh ${ }^{9}$ who reports an improving coverage in emergency obstetric care (EmOC) services, in all districts in Bangladesh during this period which in turn triggered births in EmOC facilities as well as the number of complications treated (including caesarean section) in these facilities. Lifesaving technology for women with obstetric complications has been established in rural health centres through extensive training of a wide ranging health professionals without relying on specialist doctors.

\footnotetext{
${ }^{9} \mathrm{http} / / /$ www.unicef.org/bangladesh/health_nutrition_407.htm.
} 


\subsection{Data description}

Our primary estimation sample consists of about 6141 children born to 4919 mothers born between 2002 and 2007. In order to check the robustness of our estimates, we also consider the subsample women with at least two children born in the 5 years immediately preceding the survey. In this case we have data on 2333 children born to 1111 mothers born between 2002 and 2007. This is our secondary estimation sample, which helps us to minimise the potential estimation bias, if any, arising from parentslevel omitted factors.

We consider four different measures of child mortality: early mortality (child dies within a week of birth, neonatal mortality (child dies within 30 days of birth), infant mortality (child dies within a year of birth) and finally child mortality (child dies within 5 years of birth). Overall 6 percent of children die before their $5^{\text {th }}$ birthday but this is as high as 7.6 percent for children born to adolescent mothers. Early, neonatal and infant mortality rates are all significantly higher for children born to adolescent mothers.

Early childbearing is widely prevalent in our sample. Overall 38 percent of children are born to women less than 20 years old at the time of the childbirth. This percentage is as high 76 percent for the first-born and falls steadily thereafter. Early childbirth has a significant effect on child mortality - nearly 15 percent of children born to adolescent mothers die before the fifth birthday. The corresponding figure is 9.5 percent for children born to non-adolescent mothers. Just about 13 percent of children born to adolescent mothers are born in a hospital, compared to 18 percent of children born to non-adolescent mothers (the difference is statistically significant with a p-value $=0.02$ ). Overall less than 17 percent of all births takes place at a hospital. Figure 1 presents the non-parametric lowess plots of the relationship between age of the mother at birth and the four different measures of child mortality. There is a systematic negative relationship evident for all four measures so that child mortality risks decline as age at birth increases. There is a considerable regional variation in the extent of early births, choice of health inputs and child mortality rates (see Table 2). The proportion of adolescent births varies from 0.38 in Rajshahi to 0.24 in Sylhet while the rate of hospital delivery ranges between 25.5 percent in Khulna to 10.7 percent in Sylhet. In terms of child mortality rates, Sylhet appears to be the worst 
performing division, with early, neonatal, infant and child mortality rates all being higher than the national average. In our econometric analysis we include a set of regional dummies to account for the unobserved inter-regional variation in health infrastructure availability as well as their usage. Table 3 summarises the selected descriptive statistics for the two samples used here for the purpose of the analysis.

\section{Estimation strategy}

This section explains the estimation issues and identification strategy. In this section we explain the econometric issues involved in determining child health, after resolving the simultaneity between hospital delivery and child health and also controlling for all other exogenous factors that may also influence child health.

\section{$\underline{3.1}$ Determination of child mortality}

The primary variable of interest in our analysis is child mortality and we use four different measures of child mortality in this respect including early mortality, neonatal mortality, infant mortality and also child mortality. The unit of analysis is a child $i$ born to a particular woman $j$. There might be multiple children born to the same mother during the period under consideration, which enables us to identify mother/household specific unobserved effects. The estimating equation for infant mortality is specified as:

$$
\text { CHDEAD } D_{i j}^{*}=\beta X_{i j}+u_{i j}
$$

where $C H D E A D_{i j}^{*}$ is the propensity that a child dies within a week of birth/within 30 days of birth/within a year of birth/within 5 years of birth; $C H D E A D_{i j}^{*}$ is not observed: what we observe instead is Early mortality/Neonatal mortality/Infant mortality/Child mortality each of which is categorised as indicator variable. Here $X_{i j} \equiv\left(Z_{i j}, \xi_{i j}\right)$ is a vector of individual $\left(Z_{i j}\right)$ and parental/household and other (e.g., community) characteristics $\left(\xi_{i j}\right)$ that can potentially affect child mortality. Given the binary nature of the measure of the dependent variable in equation (1), it is estimated using maximum likelihood probit. 
Our central hypothesis is that child health outcomes would depend on parental health care choice, namely, hospital or home delivery as measured by the variable HOSPDEL that takes a value 1 if the child is delivered in a health facility as opposed to home. Among other child specific characteristics $\left(Z_{i j}\right)$ in equation (1), we include a dummy for male child, if the child is one of the twins, his/her birth order (we include birth order 1,2,3,4 to test if there is any non-linearity in the birth order effect), the age of the mother at the time of the birth of the child. ${ }^{10}$ While gender, twins variable and birth order variables account for parental preferences for human capital investment for some children against others, mother's age at the birth of the child will account for the age-related biological factors that may influence child health. The parental/household level variables $\left(\xi_{i j}\right)$ include the highest education attained by each parent (primary, middle and high schooling), wealth quantiles (the reference category being quantile 5), household religion (Muslim dummy) and rural residence (dummy), all of which would account for the effective demand for health care choice for the child. In particular, more educated and also more wealthy parents are more likely to invest more in child health while child health are likely to be worse in rural households and this can be driven by both demand (there are poorer and less wealthy households) and supply (there are scarcity of health infrastructure) factors. We also include a set of regional dummies representing each division, namely, Barisal, Chittagang, Dhaka, Khulna, Rajsahi and Sylhet, with a view to account for the unobserved division-level variation in health infrastructure as well health demand. These regional factors may also account for the unobserved variation in prices of health care goods that we cannot directly account for because of the inherent endogeneity issue. We further include dummies for birth-year to account for birth-year specific demand (at the family-level) and/or supply (e.g., introduction of new health facilities, technological innovation including new diagnostics/medicine) and also interactions between (region*birthyear) region specific birth-year level shocks that may also influence child health.

\footnotetext{
${ }^{10}$ In alternative specifications we included a dummy variable for early birth (age of the mother at the time of the birth of the child was less than 20) to categorize adolescent mothers. These results are available on request.
} 
The unmeasured determinants of child mortality $\left(u_{i j}\right)$ can be divided into two parts so that $u_{i j}=\eta_{j}+\varepsilon_{i j}$. The first part $\left(\eta_{j}\right)$ is common to all children born to a particular woman $j$ and captures mother level unobserved heterogeneity that affects the health of all children born to the same mother. This could include biological/genetic factors that are unobserved to the researcher: for example a mother might have some biological problem that is transmitted genetically to her children and results in poor health outcomes to all her children, thereby increasing the probability of the child dying. We refer to this part of the error term as the fixed mother specific effect (this is especially taken account of when we consider women with at least two children). Note that equation (1) is estimated as a random effects probit regression. $\eta_{j} \sim N\left(0, \sigma_{c}^{2}\right)$ and is assumed to be uncorrelated with other covariates. All other residual variation is captured by the child-specific error term $\varepsilon_{i j}$, with $\varepsilon_{i j} \sim N(0,1)$; unlike $\eta_{j}, \varepsilon_{i j}$ could however be correlated with other co-variates.

\section{$\underline{\text { 3.2 Endogeneity Issues and Identification }}$}

Arguably, the child specific explanatory variables $\left(Z_{i j}\right)$ include two potentially endogenous variables, namely, mother's age at birth and hospital delivery, that could be correlated with $\varepsilon_{i j}$, leading to standard endogeneity problems. Mother's age at childbirth is potentially endogenous in determining child mortality in that it is related to parental choices regarding the timing and spacing between successive births. A second potentially endogenous variable relates to hospital delivery. ${ }^{11}$ Women who choose to have children in a hospital is not necessarily a random subset of the population. Indeed we might have the possibility of negative and positive self-selection: first women who choose hospital delivery may have private information on certain aspects of her health (unobserved to the researcher), which might result in increased risk of child mortality (adverse self-selection). Alternatively, women who choose

\footnotetext{
${ }^{11}$ One can consider other possible health inputs affecting child mortality: for example tetanus vaccination during pregnancy or prenatal check up by a qualified health professional. However in neither of these cases did we have the relevant data for all children born in the 5 years preceding the survey: this information was only available for the last child born. Finally we do not include child vaccination in our set of explanatory variables, since we are restricting our analysis to children dying before the first birthday for most of our empirical analysis, because in this case vaccination would be incomplete for a number of children in the sample.
} 
hospital delivery could be low risk women, but with a strong preference for healthy children (favourable self-selection).

To account for the potential endogeneity of both age of the mother at the time of birth of the child and hospital delivery we use an instrumental variable approach. This requires us to find at least one variable that directly affects the age at birth but not child mortality (instrument relevance). We also need some other identifying variables that directly affects $2^{\text {nd }}$ potentially endogenous variable hospital delivery but not child mortality. A second condition is that these instrumental variables are uncorrelated with the error term of child mortality equation 1 (instrument validity). Further a test for overidentification is required only when we have more instruments than endogenous variable; clearly, this is a pertinent issue for this analysis, as we have two instruments respectively for hospital delivery and mother's age at birth to determine on endogenous variable child mortality. We test for instrument relevance, validity and also the validity of over-identification restriction (see further discussion in section 4).

We argue that a woman's awareness of female/child health issues and also her bargaining power in the household would influence her age at birth, especially the first birth. As such, we proxy her awareness of female/child health issues by her listening to radio/tv daily, as these child/reproductive health issues are likely to be discussed on the media regularly; also there may be advertisements for government's new initiatives, if any, on radio/tv and advice for mothers/households. Second, we use a woman's membership in any micro-finance organisation or self-help group as the relevant measure for her bargaining power which could also influence her age at the time of birth. The underlying idea is as follows. Associations may become a medium of coordination, information transfer, and representation, which may in turn create safeguards for members against socio-economic extortion. In this respect, we use factor analysis to generate a composite index called social capital that takes a value 1 if the woman in question is a member of any micro-finance (Grameen Bank) or other human development network operating in Bangladesh to empower the poor, especially women (e.g., BRAC, BRDB, Asha, Proshika). We argue that membership of any of these organizations would enhance women's empowerment and may help women having a greater say in family decision making especially relating to mother/child 
health issues. Finally, we include her husband's age and also a binary variable indicating whether the woman is the wife of the head of the household; older husbands are more likely to have a greater say in family decision making which can be further strengthened if he is also the head of the household. ${ }^{12}$

Second, as indicated earlier, we use the exogenous variation in household's access to various modern and traditional health facilities in the neighbourhood as the relevant instrument for hospital delivery. Using 2007 BDHS data, we generate various binary variables to indicate access to modern health facilities, namely, district hospital, maternal care and welfare centre (mcwc), thana health centre (thc) and family welfare centre (fwc) provided by the government for determination of hospital delivery. We include a further binary variable to indicate if there are access to traditional ayurvedic/unani health centres in the primary sampling unit the household is residing. The underlying idea is that given the supply of traditional and modern health care facilities, households, within a Beckerian framework, would choose the optimal health care subject to the cost considerations and the associated budget constraint.

While it is true that a lower age of the mother at the time of the birth of the child has adverse consequences on the health of the child (contributes to an increase in child mortality), we argue that hospital delivery is an essential intervention that may help to reduce these adverse effects net of possible costs. To examine this hypothesis we include an interaction term (Age at birth $\times$ Hospital delivery) as an additional explanatory variable in the estimation of child mortality equation (1). The underlying ideas is that the estimated coefficient of the interaction term would capture the differential effect of hospital delivery for a given age at birth of the mother. This interaction coefficient therefore allows us to identify the effect of hospital delivery on adolescent mothers when age at birth $<=19$.

Thus the final mortality equation that we estimate is given by:

12 One may however argue that women with greater bargaining power on this account may also have time constraint to look after their children thus adversely affecting child health as well, which may invalidate this instrument. Note however that women who are members of micro-finance or self-help group are primarily selfemployed rather than working for others. As such they are likely to have flexibility of hours, thus minimising any impact on child health. The latter does not necessarily make our instrument invalid. In fact, our instrument would still be valid so long as the link between women's empowerment and child health is indirect. Indeed all our tests support the relevance and validity of this instrument (see further discussion in section 4). 
$\operatorname{CHDEAD}_{i j}^{*}=\beta_{0}+\beta_{1} \operatorname{Hospdel}^{\wedge}{ }_{i j}+\beta_{2} \operatorname{AgeatBirth}_{i j}{ }_{i j}+\beta_{3}\left(\operatorname{Hospdel}_{i j}^{\wedge} * \operatorname{AgeatBirth}_{i j}{ }_{i j}\right)+\beta_{x} X_{i j}+u_{i j}$

In equation (2) $\mathrm{Hospdel}^{\wedge}$ and $\mathrm{AgeatBirth}^{\wedge}$ are the two instrumental variables obtained from the first stage estimates of these variables (see Appendix Tables A3 and A4 and also discussion in section 4). After controlling for all other factors $\mathrm{X}$ that may influence various measures of child mortality, we are particularly, interested in the estimated coefficient of the interaction term since it provides the differential effect of hospital delivery for a given age at birth of the mother. For hospital delivery to be beneficial for mothers of a given age, we expect this interaction coefficient to be negative and statistically significant.

In order to ascertain the effect of hospital delivery on child health specifically among adolescent mums aged 13-19 years, we further estimate an alternative model using mother's age at birth group $\mathrm{k}=0,1,2,3$ respectively for $13-19,20-24,25-29$ and 30-34 (reference category being women aged 35 years and above) and specifically focus on the interaction of (Hospdel ${ }^{\wedge}$ agep0) where agep0 is the predicted probability of child birth for mother's aged 13-19 years derived from the first stage estimates (see Table A5 and also discussion in section 4.4). The advantage of this methodology is that we continue to use the full sample rather than truncating hospital delivery by mother's age at birth category at birth.

\section{Results}

We start with the full sample estimates of various mortality rates under consideration. Despite having a very rich set of data, no one can deny the influence of omitted variables. Hence we next move on to consider the household fixed effects estimates of these mortality rates, which allows us to minimise the household-level omitted variable bias, as we exploit the within household variation in mortality rates among children born to same parents.

\subsection{First stage estimates of Mother's age at birth and hospital delivery}


Table A4 summarises the probit marginal effects estimates of hospital delivery. We show estimates for the full sample (column 1) and also for the subsample of mothers with at least two children (column 2). Ceteris paribus, we find that households from neighbourhoods with family welfare clinics are significantly more likely to have hospital delivery while those from neighbourhoods with alternative medicine are less likely to do so. Note however that access to other modern health facilities do not significantly increase hospital delivery, highlighting that access may not necessarily boost usage because of supply constraints discussed in the introduction. Among other results, women with more schooling and also husbands with more schooling are more likely to have hospital delivery while those from Muslim households are less likely to do so.

Second, we obtain the ols estimates of mother's age at birth of the child as summarised in Appendix Table A5. We show the estimates for the full sample (column 1) and also those for the subsample (column 2). Ceteris paribus, we find that measures of woman's bargaining including index of social capital, being the wife of the head of the household and also husband's age significantly increase the woman's age at birth while listening to tv/radio does not matter in this respect.

We use these first stage estimates hospital delivery and mother's age at birth to generate their predicted values which are then used as IVs for hospital delivery and age at birth to estimate various child mortality indices shown in Table 4 (full sample) and also Tables 6 and 8 (subsample of women with at least two children).

\subsection{Full sample estimates of child mortality}

The primary variables of interest for the analysis in this paper relate to the four mortality indices including early mortality, neo-natal mortality, infant mortality and child mortality. Given each of these mortality indices is binary in nature, we estimate four different probit models. We start with the noninstrumented (non-iv) probit maximum likelihood non-iv estimates for the full sample as summarised in Appendix Table A2. However these non-iv results are likely to be biased as there are two potentially endogenous explanatory variables, namely, mother's age at birth, and hospital delivery. 
So we move on to Table 4 that summarises the full sample estimates of mortality rates; here we instrument these two potentially endogeneous explanatory variables using estimates shown in Appendix Tables A3 (for hospital delivery) and Table A4 (for mother's age at birth). Before analysing these results, let us consider the exogeneity tests for instrument relevance, validity and over-identification as summarised in Table 4. First, instrument relevance test (chi-square) statistics are statistically significant for both hospital delivery and mother's age at birth equations, suggesting that these instruments together explain a significant variation in hospital delivery and mother's age at birth respectively. Second, we test if the instruments are uncorrelated with the residuals of the mortality equations as captured by the instrument validity test chi-square statistics. Since none of the test statistics are statistically significant, we accept the null hypothesis of exogeneity. Finally, we test for over-identification as we have 2 instruments (one for hospital delivery and a second one for mother's age at birth) and one endogenous variable for each selected mortality index. Again, chi-square test statistics suggest that all the p-values are large so that we accept the null hypothesis that the over-identification restrictions are valid.

After controlling for all other factors that may influence selected mortality rates, we find that the estimated coefficients of the interaction term (hospdel*age) at birth turn out to be negative and statistically significant in columns 1-4 of Table 4. In other words, institutional (as opposed to home) delivery is likely to be associated with significantly lower early, neonatal, infant and child mortality rates for a given age at birth of the mother in our sample. We take this as evidence that this direct public health intervention (as opposed to imposing minimum age at marriages or schooling to delay marriage) is likely to be effective in reducing child mortality rates even when a child is born to a teenage mother.

Table 5 shows the predicted probability estimates of early, neo-natal, infant and child mortality rates for different values of mother's age at birth and hospital delivery obtained by using Table 4 estimates. The average mortality rates for all births turn out to be about $5 \%$ for child mortality between 1-5 years of age of a child. Note that the corresponding mortality rate is about $4 \%$ among mothers who are $>=20$ years old while it increases to about $6.4 \%$ for younger teen mothers. Hospital delivery among teen mothers can, however, lower child death from $6.4 \%$ to $4.6 \%$, which is a significant benefit relative to the teen mothers with home delivery. This can be contrasted with the variations in the child mortality 
by access to various health facilities in the neighbourhood. Medically, risks of child mortality is high during the neo-natal period (WHO 2006). We find that the risk of neonatal mortality among adolescent mothers decreases by about 1.3 percentage points if the child birth takes place at a hospital rather than at home. The average neonatal mortality is 0.05 among adolescent mums so that the hospital delivery can help averting about 26\% death among adolescent mothers within the first month of child birth. It is because having a birth at the hospital as opposed to home ensures the access to the medical experts who can employ all the modern diagnostic tests and medications which may help a newborn to survive.

\subsection{Household fixed effects estimates of child mortality indices}

We next consider the household fixed effects estimates of selected mortality indices for children aged 5 or under in our sample for households with two or more children (see Table 6); this allows us to exploit the variation in mortality outcomes of children born to same mother, thus helping us to net out the unobserved mother/family-level factors. As in Table 4, we use the instruments for the two potentially endogenous variables, namely, hospital delivery and mother's age at birth, using first stage estimates of these variables as summarised in column (2) of Appendix Tables A3 and A4 respectively.

Finally, we include these IVs for age at birth and hospital delivery to obtain the household FEIV estimates of selected mortality rates as summarised in Table 6. As in Table 4, we find from Table 6 that these instruments satisfy instrument relevance, validity and over-identification restrictions so that we can proceed to analyse these results. Controlling for all other factors, there is evidence of a negative and statistically significant estimate of (hospdel*ageatbirth) in each column of the Table. As before, hospital delivery lowers early, neo-natal, infant and child mortality for a given age at birth and the marginal effect of the interaction coefficient increases as we move from early mortality to child mortality. We then turn to Table 7 that shows the predicted estimates of child mortality rates. Compared

to Table 5, predicted probability estimates of neonatal mortality rates seem to be higher when we consider within household variation in neonatal mortality (using the household fixed effects estimates). While the rate is about $8 \%$ for all births, it is about $11 \%$ among adolescent mothers aged below 20 years. The neo-natal mortality rate, however, declines to about 9.5\% among adolescent mothers if the 
child is delivered in the hospital, thus highlighting the extent of additional lives saved due to hospital delivery, after controlling for all other factors. We prefer the household fixed effects estimates for mothers with at least 2 children as it minimises the bias arising from the omitted household-level variables as we consider the children born to the same mother though it remains much unexplored in the literature. Evidently, relative to the pooled sample, the extent of mortality risks are higher when we consider the household fixed effects estimates though as before these estimates highlight the significant impact of institutional delivery for saving lives of newborn child in our sample.

\subsection{Household fixed-effects estimates with categorical age at birth variable}

So far we have used the continuous age at birth variable that allows us to find the effect of hospital delivery for a given age at birth. We are however particularly interested to find the effect of hospital delivery on adolescent mothers aged 13-19 years. In doing so, we shall, in this section, split the continuous mother's age at birth into various groups to generate the following categorical variable.

Age_at_birth_gr $=0$ if $13<$ age at birth $<=19$

$$
\begin{aligned}
& =1 \text { if } 19<\text { age at birth }<=24 \\
& =2 \text { if } 24<\text { age at birth }<=29 \\
& =3 \text { if } 29<\text { age at birth }<=34 \\
& =4 \text { if age at birth }>=35
\end{aligned}
$$

A simple frequency distribution of this categorical variable suggests that about $32 \%$ of sample women at child birth before reaching their 20th birthday, another 32\% had birth between 20-24 years of age while only 5.5\% sample women had births when they were 35 years or above. Given the categorical nature of the age variable we use a multinomial logit model to determine the new age at birth for mothers with at least two children, with a view to explore if the same set of factors may determine the likelihood of child birth at different age groups differently (see Appendix Table A5). As before, greater social capital, husband's age and being head's wife are found to significantly lower the likelihood of being mothers during teen years (age group 0 ) and also between 20-24 years of age (age group 1 ) relative to the reference category of mothers aged 35 years and above. We use these first stage estimates to predict 
the probability of being mum at different age groups, namely, agep0, agep1, agep2, agep3 respectively for 13-19, 20-24, 25-29 and 30-34 years age groups (reference category being women aged 35 years and above), which are then used to determine the selected child mortality indices in our sample.

The resultant child mortality estimates are summarised in Table 8 for households with at least two children. While (agep0*hospdel_iv) shows the marginal effect of hospital delivery among teen mums in pre-2005 years, (post* agep0*hospdel_iv) shows the corresponding marginal effect of hospital delivery among adolescent mothers in the post-2005 years. Note that the latter is negative and statistically significant (though the corresponding effect is not significant for the pre-2005 years) in columns (1)-(3) of the Table, suggesting that hospital delivery significantly lowers early, neonatal and infant mortality rates among young teen mums only in the post-2005 year; clearly the effect is not significant in column (4) showing child mortality estimates. Table 9 shows the corresponding predicted probability estimates obtained by using the Table 8 estimates. Note that the predicted probability of neonatal mortality is about 0.14 among adolescent mothers in the pre-2005 years even when a birth takes place in a hospital. But it comes to about $6.6 \%$ in the post 2005 years among adolescent mothers with hospital delivery. This highlights a significant benefit of the completion of the WHP which boosted EmOC and also ensured a women-friendly environment in the hospitals, thus encouraging households to make use of these facilities.

\section{Conclusion}

Each year, nearly 4 million newborns in the developing world die, primarily due to treatable and preventable causes. Most of these deaths could be avoided through direct and affordable public health interventions like hospital as opposed to home delivery. We consider the case of Bangladesh where high incidence of infant mortality is related to early marriage and early childbirth. While there is a sizeable literature (e.g., see Geronimus and Korenman, 1992) on teen pregnancy in developed countries, little is known about adolescent child birth in low-income countries like Bangladesh.

Using 2007 BDHS data, we find that the incidence of hospital delivery is particularly low (only about 13\%) among young adolescent mothers who experience higher than average child mortality risks 
especially during the neo-natal period. Accordingly, the present paper examines the effect of hospital delivery, a direct public health intervention, on selected indices of mortality indices among young children aged 5 years and under. This is because hospital delivery, as opposed to home delivery, ensures that the young mother and the child receive the benefit of timely medical care, modern diagnostics and modern medicine too while the vast majority of women having child birth at home are deprived of these facilities. Our preferred estimates come from household fixed effects estimates with IV for two potentially endogenous variables, namely, hospital delivery and mother's age at birth, for households with at least two children. Thus exploiting the within household variation in selected child mortality indices, we find a significant beneficial effect of hospital delivery on these child mortality indices even among adolescent mothers, after controlling for various observable/unobservable individual, household and location specific characteristics. In addition to socio-cultural prejudice, one of the primary reasons for high incidence of home delivery is the limited access to primary health care, especially in the remote areas of the country. Our results suggest that the beneficial effect of hospital delivery has been greater in the post-2005 years after the Women's Health Project was over, which boosted access to EmOC and also popularised the use of women friendly hospitals in the neighbourhood. The finding that hospital delivery can redress the adverse effects of adolescent childbirth on child survival implies that one has in principle identified a convenient policy instrument of encouraging use of hospital delivery in the short run provided the underlying costs are not exorbitant.

\section{References}

Akhter, H. (2001) 'Expanding Access: Country Report Bangladesh', BIRPERHT, Bangladesh. http://www.tingsene.se/expacc/reports/BanglCR.html[10/03/2015 22:34:48]

Akter, R., N. Akter, S. Shafique, F. Bhuyan, C. Witten and S. d. Pee. (2007). Early Marriage and Early ChildBearing among Women in Rural Bangladesh, ICDDRB. http://www.icddrb.org/images/11thAscon_Orals Scientific-Session-3.pdf

Arunachalam, R. and S. Naidu (2008): "The Price of Fertility: Marriage Markets and Family Planning in Bangladesh", Mimeo, Department of Economics, University of Michigan.

Banerjee, A. and Duflo, E. (2006). Addressing absence. Journal of Economic Perspectives, 20(1):117. 
Begum, S., T. Ensor, P. Dave-Sen. 2000. 'The Public-Private Mix in Health Care in Bangladesh', Health Economics Unit. Ministry of Health and Family Welfare in Bangladesh.

Bryce, J., Shams el Arifeen, George Pariyo, Claudio F Lanata, Davidson Gwatkin, Jean-Pierre Habicht, and the Multi-Country Evaluation of IMCI Study Group. 2003. 'Reducing Child Mortality: Can Public Health Deliver? Lancet.

Costello, and Nahar. 1998. The hidden cost of 'free' maternity care in Dhaka, Bangladesh. Health Policy Plan 13(4):417-22.

Cockcroft, A. L. Monasta. J. Onishi, E. Karim. 1999. Health and Population Sector Programme: Baseline Service Delivery Survey 1998-2003', Ministry of Health and Family Welfare,

Chaudhury, N \& Jeffrey S. Hammer, 2004. "Ghost Doctors: Absenteeism in Rural Bangladeshi Health Facilities," World Bank Economic Review, 18(3), pages 423-441.

Darmstadt, G. L., Lee, A. C., Cousens, S., Sibley, L., Bhutta, Z. A., Donnay, F., Osrin, D., Bang, A., Kumar, V.,Wall, S. N., Baqui, A., and Lawn, J. E. (2009). 60 million non-facility births: Who can deliver in community settings to reduce intrapartum-related deaths? International Journal of Gynecology \& Obstetrics, 107, Supplement (0):S89-S112.

Field, E. and A. Ambrus (2008): "Early Marriage, Age of Menarche and Female Schooling Attainment in Bangladesh", Journal of Political Economy, 116(5), 881 -930.

Filippi, V., Ronsmans, C., Campbell, O. M., Graham,W. J., Mills, A., Borghi, J., Koblinsky, M., and Osrin, D. (2006). Maternal health in poor countries: the broader context and a call for action. The Lancet, 368(9546):1535-1541.

Geronimus, A. T. and S. Korenman (1992): "The Socioeconomic Consequences of Teen Childbearing Reconsidered", Quarterly Journal of Economics, 107(4), 1187 - 1214.

Haque, Md A, V. R. Louis, R. Phalkey and R. Sauerborn 2014. Use of traditional medicines to cope with climate-sensitive diseases in a resource poor setting in Bangladesh', BMC Public Health 2014, 14:202.

Islam, M.T., M.M. Hossain, M.A. Islam, Y.A. Haque. 2005. 'Improvement of coverage and utilization of EmOC services in southwestern Bangladesh' International Journal of Gynecology and Obstetrics (91): 298-305.

Maitra, P. (2004): "Parental Bargaining, Health Inputs and Child Mortality in India", Journal of Health Economics, 23(259 - 291).

Maitra, P. and S. Pal (2008): "Birth Spacing, Fertility Selection and Child Survival: Analysis using a Correlated Hazard Model", Journal of Health Economics, 27(3), 690 - 705.

Mazumdar, S., Mills, A., and Powell-Jackson, T. (2011). Financial Incentives in Health: New Evidence from India's Janani Suraksha Yojana. SSRN Working Paper. Available at SSRN: http://ssrn.com/abstract=1935442.

Pal, S. (1999): "An Analysis of Childhood Malnutrition in Rural India: Role of Gender, Income and Other Household Characteristics", World Development, 27(7), 1151 - 1171. 
Panis, C. W. A. and L. A. Lillard (1994): "Health inputs and child mortality: Malaysia", Journal of Health Economics, 13(4), 455-489.

Planning Commission. 2013. 'Millennium Development Goals: Bangladesh Progress Report 2012', General Economic Division, Bangladesh Planning Commission.

Randive, B., M. San Sebastian, A. De Costa and L. Lindholm. (2014). 'Inequalities in institutional delivery uptake and maternal mortality reduction in the context of cash incentive program, Janani Suraksha Yojana: Results from nine states in India', Social Science and Medicine 123: 1-6.

Reynolds, H. W., E. L. Wong and H. Tucker (2006): "Adolescents' Use of Maternal and Child Health Services in Developing Countries", International Family Planning Perspectives, 32(1).

Rosenzweig, M. R. and T. P. Schultz (1982): "Market Opportunities, Genetic Endowments and Intrafamily Resource Distribution: Child Survival in Rural India", American Economic Review, 72(4), $803-815$.

Schuler, S., F. Islam, K. Islam and G. Nanda (2005). Early marriage and childbearing in rural Bangladesh. American Public Health Association Meeting. Philadephia.

Senderowitz, J. and J. M. Paxman (1985): "Adolescent Fertility: Worldwide Concerns", Population Bulletin, 40(2), 3 - 51.

WHO (2006). Working Together for Health - The World Health Report 2006. World Health Organization.

WHO. (2007) 'Bangladesh Trains Health Workers to Reduce Maternal Mortality', Country case study, Global Health Workforce Alliance. 
Table 1. Maternal and child health status: Key statistics for Bangladesh 2007

\begin{tabular}{lc}
\hline Variables & Values \\
\hline Early mortality (first born child) & $0.0417(0.20)$ \\
Neo-natal mortality (first born child) & $0.0530(0.2242)$ \\
Infant mortality (first born) & $0.0619(0.2410)$ \\
Child mortality (first born ) & $0.0672(0.2506)$ \\
Maternal mortality ratio (deaths per 1000 births) & $320^{[1]}$ \\
Births for women aged 15-19 (per 1000) & 120 \\
Antenatal care coverage (pregnant women attend once, \%) & 49 \\
Births delivered at home (\%) & 90 \\
Births delivered at a public or private health centre (\%) & 9 \\
Delivery assistance from: & \\
Traditional birth attendants (\%) & 77 \\
Relatives and friends (\%) & 9 \\
Medically trained providers (\%) & 13 \\
Treatment for complications from: & \\
Medically trained provider (\%) & 29 \\
Unqualified provider (\%) & 33 \\
Did not seek help (\%) & 38 \\
\hline
\end{tabular}

Source: BDHS 2007

Note: ${ }^{[1]}$ From Bangladesh Maternal Health Services and Maternal Mortality Survey 2001. The State of the World's Children Report 2007 puts MMR at 380. 
Table 2. Regional variation in child mortality rates, age at birth and hospital delivery

\begin{tabular}{lccccccc}
\hline \multicolumn{7}{c}{} & \multicolumn{7}{c}{ Means (standard deviations) } \\
\hline & $\begin{array}{c}\text { Early } \\
\text { mortality }\end{array}$ & $\begin{array}{l}\text { Neonatal } \\
\text { mortality }\end{array}$ & $\begin{array}{c}\text { Infant } \\
\text { mortality }\end{array}$ & $\begin{array}{c}\text { Child } \\
\text { mortality }\end{array}$ & Age at birth & Early birth & $\begin{array}{c}\text { Hospital } \\
\text { delivery }\end{array}$ \\
\hline Barisal & 0.029 & 0.034 & 0.048 & 0.053 & 23.497 & 0.300 & 0.131 \\
& $(0.168)$ & $(0.182)$ & $(0.214)$ & $(0.224)$ & $(5.958)$ & $0.458)$ & $(0.338)$ \\
Chittagong & 0.023 & 0.034 & 0.046 & 0.058 & 23.213 & 0.319 & 0.153 \\
& $(0.149)$ & $(0.181)$ & $(0.209)$ & $(0.234)$ & $(5.975)$ & $(0.466)$ & $(0.360)$ \\
Dhaka & 0.027 & 0.036 & 0.045 & 0.047 & 23.099 & 0.315 & 0.193 \\
& $(0.161)$ & $(0.186)$ & $(0.208)$ & $(0.211)$ & $(5.824)$ & $(0.465)$ & $(0.395)$ \\
Khulna & 0.031 & 0.038 & 0.043 & 0.046 & 22.325 & 0.378 & 0.275 \\
& $(0.173)$ & $(0.191)$ & $(0.204)$ & $(0.210)$ & $(5.679)$ & $(0.485)$ & $(0.447)$ \\
Rajshahi & 0.034 & 0.046 & 0.050 & 0.052 & 22.494 & 0.380 & 0.183 \\
& $(0.182)$ & $(0.209)$ & $(0.218)$ & $(0.222)$ & $(5.93)$ & $(0.486)$ & $(0.387)$ \\
Sylhet & 0.040 & 0.062 & 0.083 & 0.091 & 24.732 & 0.244 & 0.107 \\
& $(0.197)$ & $(0.241)$ & $(0.277)$ & $(0.288)$ & $(6.509)$ & $(0.430)$ & $(0.309)$ \\
\hline Bangladesh & 0.030 & 0.042 & 0.053 & 0.059 & 23.286 & 0.319 & 0.169 \\
& $(0.171)$ & $(0.200)$ & $(0.224)$ & $(0.235)$ & $(6.051)$ & $(0.466)$ & $(0.375)$ \\
\hline
\end{tabular}


Table 3: Selected Descriptive Statistics

\begin{tabular}{lcrrrrr}
\hline & \multicolumn{3}{l}{ Full sample } & \multicolumn{3}{l}{ Households with >=2 children } \\
Variable & Obs & \multicolumn{1}{l}{ Mean } & Std. Dev. & \multicolumn{1}{l}{ Obs } & \multicolumn{1}{l}{ Mean } & \multicolumn{1}{c}{ Std. Dev. } \\
\hline Earlymortality & 6141 & 0.030288 & 0.171393 & 2333 & 0.058294 & 0.234349 \\
Neomortality & 6141 & 0.041687 & 0.199889 & 2333 & 0.079297 & 0.27026 \\
Infant mortality & 6141 & 0.053086 & 0.224223 & 2333 & 0.1003 & 0.300464 \\
Child mortality & 6141 & 0.058785 & 0.235241 & 2333 & 0.110159 & 0.313155 \\
Male & 6141 & 0.507246 & 0.499988 & 2333 & 0.495071 & 0.500083 \\
Twin & 6141 & 0.024426 & 0.203526 & 2333 & 0.064295 & 0.326342 \\
Hospital delivery & 6141 & 0.169028 & 0.374807 & 2333 & 0.103301 & 0.304416 \\
Age at birth & 6141 & 23.28562 & 6.050722 & 2333 & 22.75611 & 5.550958 \\
Post-2005 & 6141 & 0.474353 & 0.499382 & 2333 & 0.456494 & 0.49821 \\
Muslim & 6141 & 0.911904 & 0.283458 & 2333 & 0.926275 & 0.261379 \\
Mother's edn: Primary & 6141 & 0.31363 & 0.464006 & 2333 & 0.339906 & 0.473779 \\
Mother's edn: middle & 6141 & 0.340987 & 0.47408 & 2333 & 0.294042 & 0.455709 \\
Mother's edn: higher & 6141 & 0.073115 & 0.260347 & 2333 & 0.036005 & 0.186343 \\
Father's age & 6141 & 35.23021 & 8.570137 & 2333 & 35.17252 & 8.159759 \\
Father's edn: primary & 6141 & 0.284644 & 0.451282 & 2333 & 0.301329 & 0.458934 \\
Father's edn: middle & 6141 & 0.255333 & 0.436084 & 2333 & 0.207458 & 0.405573 \\
Father's edn: higher & 6141 & 0.118873 & 0.323666 & 2333 & 0.078011 & 0.268247 \\
Social capital index & 6141 & 0.362644 & 0.480802 & 2333 & 0.355336 & 0.478717 \\
Listens to radio/tv daily & 6141 & 0.347663 & 0.476267 & 2333 & 0.285041 & 0.451531 \\
Wealth quintile 1 & 6141 & 0.198665 & 0.399028 & 2333 & 0.232748 & 0.422673 \\
Wealth quintile 2 & 6141 & 0.208598 & 0.406339 & 2333 & 0.237891 & 0.425883 \\
Wealth quintile 3 & 6141 & 0.187592 & 0.390418 & 2333 & 0.198028 & 0.398599 \\
Wealth quintile4 & 6141 & 0.186615 & 0.389634 & 2333 & 0.16631 & 0.372438 \\
Rural & 6141 & 0.34229 & 0.474515 & 2333 & 0.294899 & 0.456095 \\
\hline
\end{tabular}


Table 4. Probit marginal effects IV estimates of child health: Full sample

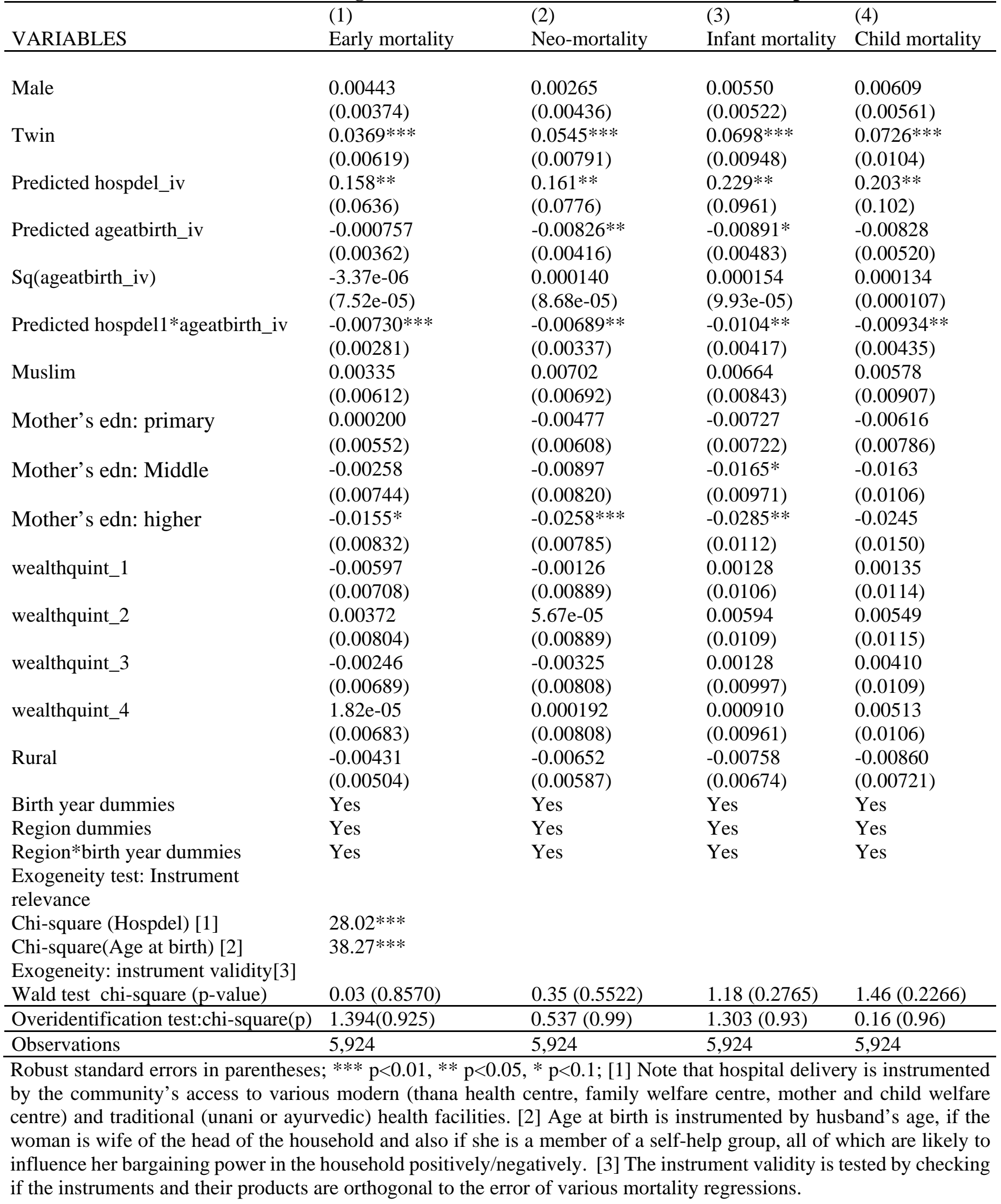


Table 5. Predicted probability estimates of child mortality

\begin{tabular}{|c|c|c|c|c|}
\hline Sample & $\begin{array}{l}\text { Early } \\
\text { mortality }\end{array}$ & Neo mortality & Infant mortality & $\begin{array}{l}\text { Child } \\
\text { mortality }\end{array}$ \\
\hline All birth predicted & 0.023 & 0.032 & 0.042 & 0.048 \\
\hline Mother's age>19 & 0.016 & 0.023 & 0.033 & 0.038 \\
\hline Mother's age $<=19$ & 0.039 & 0.049 & 0.056 & 0.064 \\
\hline $\begin{array}{l}\text { Mother's age }<=19 \& \text { no } \\
\text { hospital delivery }\end{array}$ & 0.051 & 0.061 & 0.063 & 0.066 \\
\hline $\begin{array}{l}\text { Mother's age }<=19 \& \\
\text { hospital delivery }\end{array}$ & 0.036 & 0.048 & 0.046 & 0.046 \\
\hline $\begin{array}{l}\text { Reduction in morality due to } \\
\text { hospital delivery for early } \\
\text { birth }\end{array}$ & 0.015 & 0.013 & 0.017 & 0.020 \\
\hline All birth (observed) & 0.030 & 0.042 & 0.053 & 0.059 \\
\hline
\end{tabular}

Notes: These predicted probabilities are calculated using Table 4 estimates 
Table 6. Probit marginal effects household fixed effects IV estimates of child mortality indices for mothers with 2 or more children

\begin{tabular}{lllll}
\hline & $(1)$ & $(2)$ & $(3)$ & $(4)$ \\
VARIABLES & Early mortality & Neo-mortality & $\begin{array}{l}\text { Infant mortality } \\
\text { Child mortality }\end{array}$ \\
\hline & 0.176 & & & \\
Predicted hospital delivery & $(0.142)$ & 0.303 & $0.598^{* *}$ & $0.676^{* *}$ \\
& 0.00599 & $(0.188)$ & $(0.290)$ & $(0.305)$ \\
Predicted age at birth & $(0.0111)$ & -0.00766 & -0.0205 & -0.0182 \\
& -0.000261 & $(0.0136)$ & $(0.0198)$ & $(0.0209)$ \\
Predicted Sq(ageatbirth) & $(0.000254)$ & $-1.65 \mathrm{e}-07$ & 0.000179 & 0.000128 \\
& $-0.0101^{*}$ & $(0.000306)$ & $(0.000433)$ & $(0.000461)$ \\
Predicted hospdelivery*ageatbirth & $(0.00574)$ & $-0.0168^{*}$ & $-0.0313^{* *}$ & $-0.0347^{* *}$ \\
& Yes & $(0.00908)$ & $(0.0137)$ & $(0.0142)$ \\
Mother FE & Yes & Yes & Yes & Yes \\
Mother*Region dummies & & Yes & Yes & Yes \\
Exogeneity test: Instrument relevance & $14.76^{* * *}$ & & & \\
Chi-square (Hospdel) [1] & $30.76^{* * *}$ & & & \\
Chi-square (Age at birth) [2] & & & & \\
Exogeneity test: instrument validity[3] & $2.14(0.1419)$ & $2.06(0.1515)$ & $1.53(0.2159)$ & $2.02(0.1549)$ \\
Wald test chi-square(p-value) & $4.514(0.48)$ & $2.767(0.74)$ & $0.489(0.99)$ & $0.851(0.97)$ \\
\hline Overidentification test: chi-square(p-val) & 2,187 & 2,187 & 2,187 & 2,187 \\
\hline Observations & R & & & \\
\hline
\end{tabular}

Robust standard errors in parentheses; ${ }^{* * *} \mathrm{p}<0.01,{ }^{* *} \mathrm{p}<0.05,{ }^{*} \mathrm{p}<0.1$. Other variables are as in Table 4.

Table 7. Predicted estimates for sample with at least two children

\begin{tabular}{lll}
\hline Sample & $\begin{array}{l}\text { Early } \\
\text { mortality }\end{array}$ & Neo mortality \\
\hline All birth predicted & 0.06 & 0.0797 \\
Mother's age $>19$ & 0.044 & 0.0616 \\
Mother's age $<=19$ & 0.085 & 0.1083 \\
$\begin{array}{l}\text { Mother's age }<=19 \text { \& } \\
\text { hospital delivery }\end{array}$ & 0.751 & 0.0950 \\
\hline All birth (observed) & $\mathbf{0 . 0 5 8}$ & $\mathbf{0 . 0 7 9}$ \\
\hline
\end{tabular}

Notes: These predicted probabilities are calculated using Table 6 estimates 
Table 8. Marginal effects estimates of selected mortality indices with mother’s age group

\begin{tabular}{|c|c|c|c|c|}
\hline VARIABLES & $\begin{array}{c}(1) \\
\text { Early mortality }\end{array}$ & $\begin{array}{c}(2) \\
\text { Neo-mortality }\end{array}$ & $\begin{array}{c}\text { (3) } \\
\text { Infant mortality }\end{array}$ & $\begin{array}{c}\text { (4) } \\
\text { Child mortality }\end{array}$ \\
\hline \multirow[t]{2}{*}{ Predicted hospital del (hospdel) } & 1.444 & 0.00746 & -0.669 & -2.759 \\
\hline & $(1.357)$ & $(1.576)$ & $(1.636)$ & (1.749) \\
\hline \multirow[t]{2}{*}{ Predicted agep0: 13-19 } & $0.204^{*}$ & 0.0687 & 0.107 & 0.136 \\
\hline & $(0.108)$ & $(0.126)$ & $(0.130)$ & $(0.137)$ \\
\hline \multirow[t]{2}{*}{ Predicted agep1: 20-24 } & 0.0786 & -0.100 & -0.0709 & -0.0451 \\
\hline & $(0.132)$ & $(0.155)$ & $(0.165)$ & $(0.173)$ \\
\hline \multirow[t]{2}{*}{ Predicted agep2: 25-29 } & $0.176^{*}$ & 0.103 & 0.0769 & 0.0467 \\
\hline & $(0.0934)$ & $(0.105)$ & $(0.121)$ & $(0.130)$ \\
\hline \multirow[t]{2}{*}{ Predicted agep3: 30-34 } & 0.245 & -0.0723 & 0.0429 & 0.170 \\
\hline & $(0.261)$ & $(0.302)$ & $(0.305)$ & $(0.312)$ \\
\hline \multirow[t]{2}{*}{ Predicted agep0*hospdel_iv } & -1.302 & 0.276 & 1.026 & $3.170^{*}$ \\
\hline & (1.338) & $(1.556)$ & $(1.621)$ & $(1.753)$ \\
\hline \multirow[t]{2}{*}{ Predicted agep1*hospdel_iv } & -1.614 & -0.215 & 0.489 & 2.360 \\
\hline & (1.449) & $(1.703)$ & $(1.767)$ & $(1.830)$ \\
\hline \multirow[t]{2}{*}{ Predicted agep2*hospdel_iv } & -0.853 & 0.274 & 0.691 & $3.402 * *$ \\
\hline & $(1.070)$ & $(1.295)$ & $(1.434)$ & $(1.726)$ \\
\hline \multirow[t]{2}{*}{ Predicted agep3*hospdel_iv } & -3.681 & -1.278 & -0.263 & 2.039 \\
\hline & $(2.637)$ & $(2.977)$ & $(2.925)$ & $(2.645)$ \\
\hline \multirow[t]{2}{*}{ Post (Birth year $>=2005$ ) } & $-0.0482 * * *$ & $-0.0602 * * *$ & $-0.0598 * * *$ & $-0.0714^{* * *}$ \\
\hline & $(0.0108)$ & $(0.0128)$ & $(0.0148)$ & $(0.0157)$ \\
\hline \multirow[t]{2}{*}{ Post*predicted hospdel_iv } & $0.187 * *$ & $0.226 *$ & 0.180 & 0.000410 \\
\hline & $(0.0878)$ & (0.119) & $(0.146)$ & $(0.137)$ \\
\hline \multirow[t]{2}{*}{ Post*agep0*hospdel_iv } & $-0.346^{*}$ & $-0.490 * *$ & $-0.533^{*}$ & -0.232 \\
\hline & $(0.190)$ & $(0.239)$ & $(0.291)$ & $(0.270)$ \\
\hline Other control variables & Yes & Yes & Yes & Yes \\
\hline Mother FE & Yes & Yes & Yes & Yes \\
\hline Region FE & Yes & Yes & Yes & Yes \\
\hline Mother*region FE & Yes & Yes & Yes & Yes \\
\hline \multicolumn{5}{|l|}{ Exogeneity test: IV relevance } \\
\hline Chi-square (Hospdel) [1] & $14.76 * * *$ & & & \\
\hline Chi-square (Age at birth gr) [2] & $25.35 * * *$ & & & \\
\hline \multicolumn{5}{|l|}{ Exogeneity test: IV validity[3] } \\
\hline Wald test chi-square(p-value) & $0.17(0.9782)$ & $0.21(0.9604)$ & $0.16(0.9773)$ & $0.12(0.9883)$ \\
\hline Overidentificaton: chi-sq(P-val) & $0.114(0.9448)$ & $0.178(0.9149)$ & $0.027(0.9827)$ & $0.130(0.9370)$ \\
\hline Observations & 2,262 & 2,262 & 2,262 & 2,262 \\
\hline
\end{tabular}

Robust standard errors in parentheses; ${ }^{* *} \mathrm{p}<0.01,{ }^{* *} \mathrm{p}<0.05,{ }^{*} \mathrm{p}<0.1$; other control variables are as in Table 4 . We use the multinomial logit estimates of mother's age at birth groups (see Table 5) to generate predicted values of various age at birth groups, namely, agep0 (13-19), agep1 (20-24), agep2 (25-29), agep3 (30-34), the reference category being agep4, i.e., those 35 and above. We observe children born during 2002-2007 and generate a dummy called Post that takes a value 1 if the child is born 2005 or after with a view to assess the impact of the Women's project that was completed around this time. We also interact this dummy with hospdel_iv and agep0*hospdel_iv to account for the effect of hospital delivery among teen mums in the post 2005 years. 
Table 9. Predicted estimates for sample with at least two children

\begin{tabular}{|c|c|c|}
\hline Sample & $\begin{array}{l}\text { Early } \\
\text { mortality }\end{array}$ & Neo mortality \\
\hline All birth predicted & 0.059 & 0.079 \\
\hline $\begin{array}{l}\text { Mother's age }<=19 \text { \& } \\
\text { hospital delivery Pre-2005 }\end{array}$ & 0.106 & 0.136 \\
\hline $\begin{array}{l}\text { Mother's age }<=19 \& \\
\text { hospital delivery post-2005 }\end{array}$ & 0.05 & 0.066 \\
\hline All birth (observed) & 0.058 & 0.079 \\
\hline
\end{tabular}

Notes: These predicted probabilities are calculated using Table 8 estimates

Figure 1: Mother's age at birth and child mortality (Primary Sample)

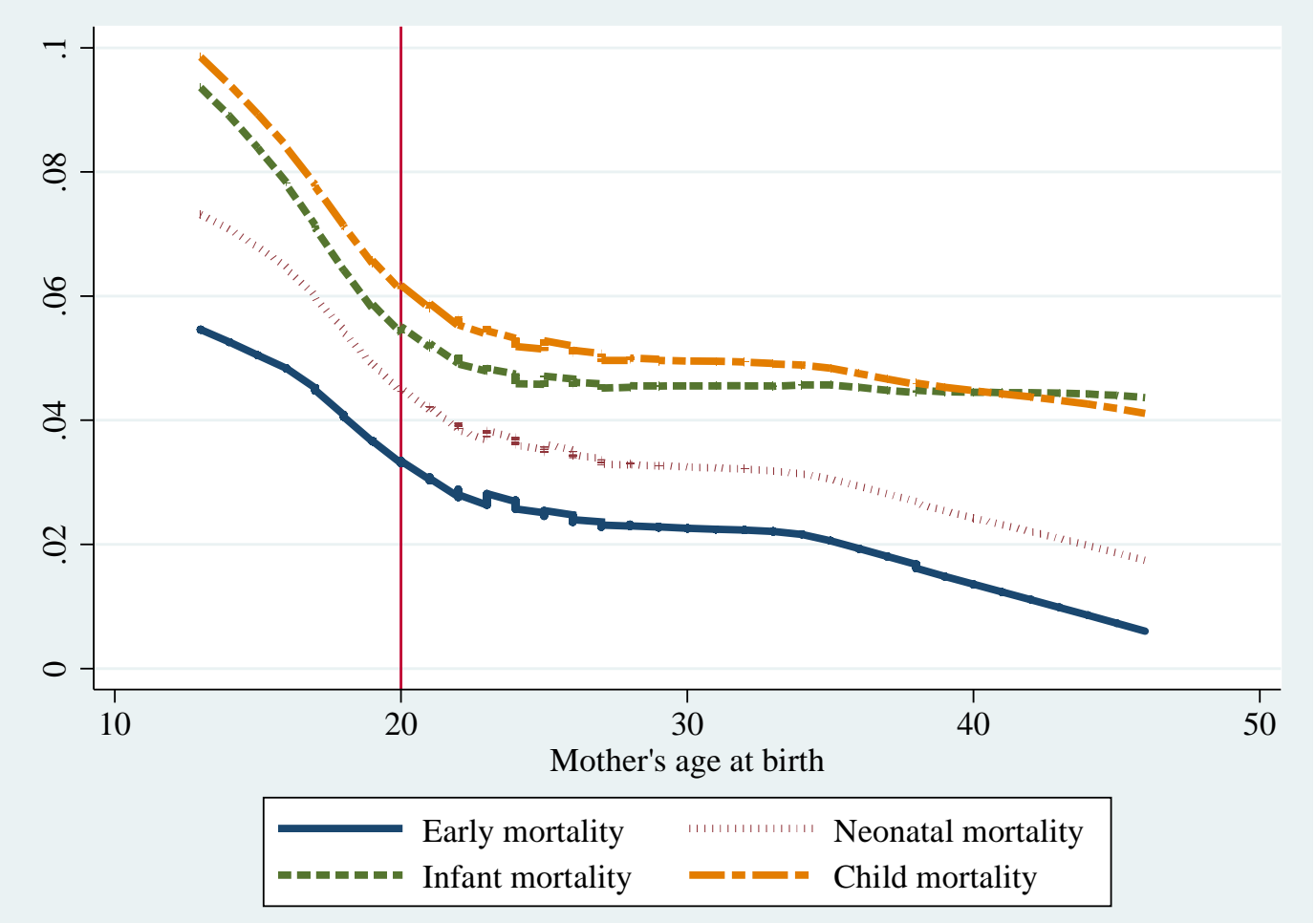


Table A1. Types of health facilities in Bangladesh

\begin{tabular}{|c|c|c|c|}
\hline $\begin{array}{l}\text { Types of health } \\
\text { facilities }\end{array}$ & Level (no) & Obstetric care provider & Expected services \\
\hline $\begin{array}{l}\text { Medical college } \\
\text { hospital }\end{array}$ & District (13) & $\begin{array}{l}\text { Specialist, MO, Nursing } \\
\text { staff }\end{array}$ & EsOC \& CEmOC \\
\hline District hospital & District (59) & $\begin{array}{l}\text { Specialist, MO, Nursing } \\
\text { staff }\end{array}$ & EsOC \& CEmOC \\
\hline \multirow{3}{*}{$\begin{array}{l}\text { Maternal and child } \\
\text { welfare centre (mcwc) }\end{array}$} & District (52) & MO, FWV, day nurse & EsOC \& CEmOC \\
\hline & Thana (24) & FWV & ANC, delivery \\
\hline & Union (11) & FWV & ANC, delivery \\
\hline $\begin{array}{l}\text { Thana health centre } \\
\text { (thc) }\end{array}$ & Thana (400) & $\begin{array}{l}\text { Medical Officer, } \\
\text { Nursing staff, FWV }\end{array}$ & EsOC \& CEmOC \\
\hline $\begin{array}{l}\text { Family welfare centre } \\
\text { (fwc) }\end{array}$ & $\begin{array}{l}\text { Union } \\
(4700)\end{array}$ & FWV, MA & ANC, delivery \\
\hline
\end{tabular}

Note: EsOC: Essential obstetric care; EmOC: Emergency obstetric care; ANC: antenatal care; MO: Medical officer; FWV: Family welfare volunteer;

Source: Akhter (2001): http://www.tingsene.se/expacc/reports/BanglCR.html[10/03/2015 22:34:48] 
Table A2. Probit Marginal effects (non-IV) estimates of child health: full sample

\begin{tabular}{|c|c|c|c|c|}
\hline VARIABLES & $\begin{array}{c}(1) \\
\text { Early mortality }\end{array}$ & $\begin{array}{c}(2) \\
\text { Neo-mortality }\end{array}$ & $\begin{array}{c}(3) \\
\text { Infant mortality } \\
\end{array}$ & $\begin{array}{c}\text { (4) } \\
\text { Child mortality } \\
\end{array}$ \\
\hline Male & $\begin{array}{c}0.00352 \\
(0.00376)\end{array}$ & $\begin{array}{c}0.00188 \\
(0.00436)\end{array}$ & $\begin{array}{c}0.00529 \\
(0.00526)\end{array}$ & $\begin{array}{c}0.00591 \\
(0.00560)\end{array}$ \\
\hline Twin & $\begin{array}{c}0.0375 * * * \\
(0.00585)\end{array}$ & $\begin{array}{l}0.0558 * * * \\
(0.00773)\end{array}$ & $\begin{array}{l}0.0716^{* * *} \\
(0.00941)\end{array}$ & $\begin{array}{c}0.0735 * * * \\
(0.0103)\end{array}$ \\
\hline Hospital delivery & $\begin{array}{l}-0.0108 \\
(0.0150)\end{array}$ & $\begin{array}{l}0.00575 \\
(0.0264)\end{array}$ & $\begin{array}{c}0.0195 \\
(0.0361)\end{array}$ & $\begin{array}{c}0.0231 \\
(0.0385)\end{array}$ \\
\hline Age at birth year & $\begin{array}{c}-0.00425^{* *} \\
(0.00208)\end{array}$ & $\begin{array}{c}-0.00578 * * \\
(0.00246)\end{array}$ & $\begin{array}{c}-0.00749 * * \\
(0.00294)\end{array}$ & $\begin{array}{c}-0.00727 * * \\
(0.00318)\end{array}$ \\
\hline Square(Age at birth year) & $\begin{array}{c}5.47 \mathrm{e}-05 \\
(4.04 \mathrm{e}-05)\end{array}$ & $\begin{array}{l}7.79 e-05 * \\
(4.73 e-05)\end{array}$ & $\begin{array}{c}0.000110^{* *} \\
(5.59 \mathrm{e}-05)\end{array}$ & $\begin{array}{l}9.97 e-05 * \\
(6.05 e-05)\end{array}$ \\
\hline Hospdel*ageatbirth & $\begin{array}{c}0.000866 \\
(0.000874)\end{array}$ & $\begin{array}{l}0.000224 \\
(0.00107)\end{array}$ & $\begin{array}{l}-0.000425 \\
(0.00130)\end{array}$ & $\begin{array}{l}-0.000419 \\
(0.00137)\end{array}$ \\
\hline Birthyear FE & Yes & Yes & Yes & Yes \\
\hline Region FE & Yes & Yes & Yes & Yes \\
\hline Region*birthyear FE & Yes & Yes & Yes & Yes \\
\hline Other variables[1] & Yes & Yes & Yes & Yes \\
\hline Observations & 6,052 & 6,052 & 6,052 & 6,052 \\
\hline
\end{tabular}

Robust standard errors in parentheses; $* * * \mathrm{p}<0.01, * * \mathrm{p}<0.05$, * $\mathrm{p}<0.1$

[1] Other variables are as in Table 4. 
Table A3. Probit marginal effects estimates of hospital delivery

\begin{tabular}{|c|c|c|}
\hline VARIABLES & (1) All & (2) Nchild $>=2$ \\
\hline Male & $\begin{array}{l}0.0208 * * \\
(0.00809)\end{array}$ & $\begin{array}{c}0.00908 \\
(0.00909)\end{array}$ \\
\hline Twin & $\begin{array}{c}0.0692 * * * \\
(0.0183)\end{array}$ & $\begin{array}{c}0.0625 * * * \\
(0.0157)\end{array}$ \\
\hline Muslim & $\begin{array}{c}-0.0647 * * * \\
(0.0183)\end{array}$ & $\begin{array}{l}-0.0387 \\
(0.0287)\end{array}$ \\
\hline Mother's edn: primary & $\begin{array}{c}0.0946 * * * \\
(0.0181)\end{array}$ & $\begin{array}{c}0.0558 * * \\
(0.0217)\end{array}$ \\
\hline Mother's edn: Middle & $\begin{array}{l}0.206 * * * \\
(0.0195)\end{array}$ & $\begin{array}{l}0.105 * * * \\
(0.0278)\end{array}$ \\
\hline Mother’s edn: higher & $\begin{array}{c}0.474 * * * \\
(0.0399)\end{array}$ & $\begin{array}{l}0.297 * * * \\
(0.0917)\end{array}$ \\
\hline Father's edn: primary & $\begin{array}{c}0.0277^{* *} \\
(0.0136)\end{array}$ & $\begin{array}{l}0.0320 * \\
(0.0166)\end{array}$ \\
\hline Father's edn: middle & $\begin{array}{c}0.0930 * * * \\
(0.0159)\end{array}$ & $\begin{array}{c}0.0473 * * \\
(0.0213)\end{array}$ \\
\hline Father's edn: higher & $\begin{array}{l}0.238 * * * \\
(0.0284)\end{array}$ & $\begin{array}{l}0.184 * * * \\
(0.0540)\end{array}$ \\
\hline Nearest hosp in the psu & $\begin{array}{l}-0.00297 \\
(0.0135)\end{array}$ & $\begin{array}{l}-0.0139 \\
(0.0231)\end{array}$ \\
\hline Nearest thc in the psu & $\begin{array}{l}-0.00201 \\
(0.0112)\end{array}$ & $\begin{array}{l}-0.0128 \\
(0.0164)\end{array}$ \\
\hline Nearest fwc in the psu & $\begin{array}{l}0.0324 * * * \\
(0.00979)\end{array}$ & $\begin{array}{c}0.0203 \\
(0.0130)\end{array}$ \\
\hline Nearest mcwc in the psu & $\begin{array}{l}0.00660 \\
(0.0103)\end{array}$ & $\begin{array}{l}0.0350 * * \\
(0.0174)\end{array}$ \\
\hline $\begin{array}{l}\text { Has access to alternative } \\
\text { medicine in the psu }\end{array}$ & $-0.0398 * * *$ & $-0.0266 * *$ \\
\hline Rural & $\begin{array}{c}(0.00845) \\
0.119 * * * \\
(0.0113)\end{array}$ & $\begin{array}{c}(0.0108) \\
0.0612 * * * \\
(0.0174)\end{array}$ \\
\hline $\begin{array}{l}\text { Mother FE } \\
\text { Region FF }\end{array}$ & $\begin{array}{l}\text { No } \\
\text { Yes }\end{array}$ & $\begin{array}{l}\text { Yes } \\
\text { Yes }\end{array}$ \\
\hline Mother*Region FE & No & Yes \\
\hline Region*Birth year FE & Yes & No \\
\hline Observations & 6,141 & 2,287 \\
\hline
\end{tabular}

Robust standard errors in parentheses

$* * * \mathrm{p}<0.01, * * \mathrm{p}<0.05, * \mathrm{p}<0.1$ 
Table A4. OLS Estimates of age at birth

\begin{tabular}{|c|c|c|}
\hline VARIABLES & (1) All & (2) Nchild $>=2$ \\
\hline \multirow[t]{2}{*}{ Muslim } & 0.173 & $-1.135 * * *$ \\
\hline & $(0.183)$ & $(0.358)$ \\
\hline \multirow[t]{2}{*}{ Mother’s edn: primary } & $-1.239 * * *$ & -0.0657 \\
\hline & $(0.151)$ & $(0.247)$ \\
\hline \multirow[t]{2}{*}{ Mother's edn: Middle } & $-2.094 * * *$ & -0.108 \\
\hline & $(0.163)$ & $(0.280)$ \\
\hline \multirow[t]{2}{*}{ Mother’s edn: higher } & 0.0715 & $3.324 * * *$ \\
\hline & $(0.274)$ & $(0.698)$ \\
\hline \multirow[t]{2}{*}{ Husband's age } & $1.164 * * *$ & $0.503 * * *$ \\
\hline & $(0.0310)$ & $(0.0537)$ \\
\hline \multirow{2}{*}{ Sq(Husband’s age) } & $-0.00827 * * *$ & $-0.00347 * * *$ \\
\hline & $(0.000381)$ & $(0.000568)$ \\
\hline \multirow[t]{2}{*}{ Father’s edn: primary } & -0.134 & -0.249 \\
\hline & $(0.138)$ & $(0.222)$ \\
\hline \multirow[t]{2}{*}{ Father's edn: middle } & 0.165 & 0.201 \\
\hline & $(0.159)$ & $(0.278)$ \\
\hline \multirow{2}{*}{ Father's edn: higher } & 0.189 & 0.265 \\
\hline & $(0.233)$ & $(0.431)$ \\
\hline \multirow[t]{2}{*}{ Social capital index } & $0.568 * * *$ & $0.549 * * *$ \\
\hline & $(0.111)$ & $(0.197)$ \\
\hline \multirow[t]{2}{*}{ Listens to tv/radio daily } & 0.0634 & -0.00874 \\
\hline & $(0.125)$ & $(0.216)$ \\
\hline \multirow[t]{2}{*}{ Nearest fwc in the psu } & 0.150 & 0.0680 \\
\hline & $(0.108)$ & $(0.188)$ \\
\hline \multirow[t]{2}{*}{ Head's wife } & $1.041^{* * *}$ & 0.0160 \\
\hline & $(0.117)$ & $(0.223)$ \\
\hline \multirow[t]{2}{*}{ wealthquint_1 } & Dropped & $-1.198 * * *$ \\
\hline & & $(0.377)$ \\
\hline \multirow[t]{2}{*}{ wealthquint_2 } & $-0.395 * *$ & $-1.313 * * *$ \\
\hline & $(0.164)$ & $(0.347)$ \\
\hline \multirow[t]{2}{*}{ wealthquint_3 } & -0.00650 & $-0.948 * * *$ \\
\hline & $(0.171)$ & $(0.349)$ \\
\hline \multirow[t]{2}{*}{ wealthquint_4 } & 0.0270 & $-1.031 * * *$ \\
\hline & $(0.193)$ & $(0.321)$ \\
\hline \multirow[t]{2}{*}{ wealthquint_5 } & $0.500 * *$ & Dropped \\
\hline & $(0.226)$ & \\
\hline \multirow[t]{2}{*}{ Rural } & -0.151 & 0.0246 \\
\hline & $(0.125)$ & $(0.219)$ \\
\hline \multirow[t]{2}{*}{ Constant } & $-7.890 * * *$ & $7.635 * * *$ \\
\hline & $(0.747)$ & $(1.312)$ \\
\hline Mother FE & No & Yes \\
\hline Birth Year FE & Yes & Yes \\
\hline Region FE & Yes & Yes \\
\hline Region*Birth year FE & Yes & Yes \\
\hline Observations & 6,012 & 2,307 \\
\hline R-squared & 0.587 & 0.724 \\
\hline
\end{tabular}


Robust standard errors in parentheses; ${ }^{* * *} \mathrm{p}<0.01$, ** $\mathrm{p}<0.05,{ }^{*} \mathrm{p}<0.1$

Table A5. Multinomial logit estimates of mother's age at birth categories for nchild $>=2$

\begin{tabular}{|c|c|c|c|c|}
\hline VARIABLES & $\begin{array}{c}\text { (1) } \\
\text { age at } \\
\text { birth }<=19\end{array}$ & $\begin{array}{c}(2) \\
19<\text { age at } \\
\text { birth<=24 }\end{array}$ & $\begin{array}{c}(3) \\
24<\text { age at } \\
\text { birth }<=29\end{array}$ & $\begin{array}{c}(4) \\
29<\text { age at } \\
\text { birth<=34 }\end{array}$ \\
\hline Muslim & $\begin{array}{l}0.459 * \\
(0.277)\end{array}$ & $\begin{array}{c}0.268 \\
(0.256)\end{array}$ & $\begin{array}{c}0.346 \\
(0.247)\end{array}$ & $\begin{array}{l}0.538 * * \\
(0.250)\end{array}$ \\
\hline Mother's edn: primary & $\begin{array}{c}1.154 * * * \\
(0.221)\end{array}$ & $\begin{array}{c}0.755^{* * * *} \\
(0.207)\end{array}$ & $\begin{array}{c}0.414 * * \\
(0.195)\end{array}$ & $\begin{array}{l}0.333^{*} \\
(0.190)\end{array}$ \\
\hline Mother's edn: Middle & $\begin{array}{c}2.208 * * * \\
(0.287)\end{array}$ & $\begin{array}{c}1.510^{* * *} \\
(0.275)\end{array}$ & $\begin{array}{c}0.987 * * * \\
(0.263)\end{array}$ & $\begin{array}{c}0.606 * * \\
(0.260)\end{array}$ \\
\hline Mother's edn: higher & $\begin{array}{l}-0.301 \\
(0.494)\end{array}$ & $\begin{array}{l}0.0563 \\
(0.459)\end{array}$ & $\begin{array}{c}0.485 \\
(0.440)\end{array}$ & $\begin{array}{c}0.442 \\
(0.439)\end{array}$ \\
\hline Husband's age & $\begin{array}{c}-1.601 * * * \\
(0.289)\end{array}$ & $\begin{array}{c}-1.288 * * * \\
(0.288)\end{array}$ & $\begin{array}{c}-0.884 * * * \\
(0.287)\end{array}$ & $\begin{array}{c}-0.556^{* *} \\
(0.283)\end{array}$ \\
\hline Sq(Husband's age) & $\begin{array}{c}0.0121 * * * \\
(0.00302)\end{array}$ & $\begin{array}{c}0.00965^{* * * *} \\
(0.00301)\end{array}$ & $\begin{array}{c}0.00653 * * \\
(0.00299)\end{array}$ & $\begin{array}{c}0.00427 \\
(0.00291)\end{array}$ \\
\hline Father's edn: primary & $\begin{array}{c}0.359 \\
(0.220)\end{array}$ & $\begin{array}{c}0.274 \\
(0.210)\end{array}$ & $\begin{array}{c}0.149 \\
(0.199)\end{array}$ & $\begin{array}{c}0.204 \\
(0.194)\end{array}$ \\
\hline Father's edn: middle & $\begin{array}{l}-0.177 \\
(0.252)\end{array}$ & $\begin{array}{l}0.0212 \\
(0.239)\end{array}$ & $\begin{array}{l}0.0354 \\
(0.224)\end{array}$ & $\begin{array}{l}0.0454 \\
(0.218)\end{array}$ \\
\hline Father's edn: higher & $\begin{array}{l}-0.616 \\
(0.389)\end{array}$ & $\begin{array}{l}-0.319 \\
(0.370)\end{array}$ & $\begin{array}{l}-0.197 \\
(0.355)\end{array}$ & $\begin{array}{l}-0.122 \\
(0.352)\end{array}$ \\
\hline Social capital index & $\begin{array}{c}-0.507 * * * \\
(0.176)\end{array}$ & $\begin{array}{c}-0.371^{* *} \\
(0.167)\end{array}$ & $\begin{array}{l}-0.0238 \\
(0.159)\end{array}$ & $\begin{array}{l}0.0815 \\
(0.156)\end{array}$ \\
\hline Listens to tv/radio daily & $\begin{array}{l}0.0919 \\
(0.225)\end{array}$ & $\begin{array}{c}0.312 \\
(0.216)\end{array}$ & $\begin{array}{c}0.316 \\
(0.209)\end{array}$ & $\begin{array}{c}0.235 \\
(0.206)\end{array}$ \\
\hline Nearest fwc in the psu & $\begin{array}{l}-0.165 \\
(0.168)\end{array}$ & $\begin{array}{l}-0.104 \\
(0.160)\end{array}$ & $\begin{array}{l}-0.118 \\
(0.153)\end{array}$ & $\begin{array}{l}-0.0717 \\
(0.151)\end{array}$ \\
\hline Head's wife & $\begin{array}{c}-1.012^{* * * *} \\
(0.264)\end{array}$ & $\begin{array}{c}-0.699 * * * \\
(0.258)\end{array}$ & $\begin{array}{l}-0.356 \\
(0.254)\end{array}$ & $\begin{array}{c}0.0548 \\
(0.257)\end{array}$ \\
\hline wealthquint_1 & $\begin{array}{c}0.696 * * \\
(0.343)\end{array}$ & $\begin{array}{c}0.950 * * * \\
(0.325)\end{array}$ & $\begin{array}{c}0.748 * * \\
(0.311)\end{array}$ & $\begin{array}{l}0.0738 \\
(0.302)\end{array}$ \\
\hline wealthquint_2 & $\begin{array}{c}1.277 * * * \\
(0.343)\end{array}$ & $\begin{array}{c}1.128 * * * \\
(0.323)\end{array}$ & $\begin{array}{c}0.955^{* * *} \\
(0.308)\end{array}$ & $\begin{array}{c}0.422 \\
(0.299)\end{array}$ \\
\hline wealthquint_3 & $\begin{array}{l}0.650 * * \\
(0.309)\end{array}$ & $\begin{array}{c}0.437 \\
(0.294)\end{array}$ & $\begin{array}{c}0.274 \\
(0.283)\end{array}$ & $\begin{array}{l}0.0171 \\
(0.279)\end{array}$ \\
\hline wealthquint_4 & $\begin{array}{c}0.718^{* *} \\
(0.290)\end{array}$ & $\begin{array}{c}0.612^{* *} \\
(0.277)\end{array}$ & $\begin{array}{c}0.210 \\
(0.271)\end{array}$ & $\begin{array}{l}-0.0581 \\
(0.269)\end{array}$ \\
\hline Rural & $\begin{array}{l}-0.0957 \\
(0.201)\end{array}$ & $\begin{array}{c}0.126 \\
(0.189)\end{array}$ & $\begin{array}{c}-0.00697 \\
(0.183)\end{array}$ & $\begin{array}{l}-0.183 \\
(0.180)\end{array}$ \\
\hline Constant & $\begin{array}{c}44.43 * * * \\
(6.908)\end{array}$ & $\begin{array}{c}37.22 * * * \\
(6.892)\end{array}$ & $\begin{array}{c}26.36 * * * \\
(6.858)\end{array}$ & $\begin{array}{l}16.16^{* * *} \\
(6.845)\end{array}$ \\
\hline Mother FE & Yes & Yes & Yes & Yes \\
\hline Birth order dummies & Yes & Yes & Yes & Yes \\
\hline Region dummies & Yes & Yes & Yes & Yes \\
\hline Observations & 6,012 & 6,012 & 6,012 & 6,012 \\
\hline
\end{tabular}

Robust standard errors in parentheses; ${ }^{* * *} \mathrm{p}<0.01,{ }^{* *} \mathrm{p}<0.05,{ }^{*} \mathrm{p}<0.1$. 